\title{
Ora (Direis) Ouvir Estrelas!: Estudo das Citações de Autores de Estratégia na Produção Acadêmica Brasileira
}

\author{
Luiz Paulo Bignetti \\ Ely Laureano Paiva
}

\section{Resumo}

Este artigo procura analisar as linhas de pensamento predominantes nos estudos de pesquisadores brasileiros de administração estratégica. Para tanto, utilizou-se um referencial teórico que classifica os principais autores da área, desde os clássicos, como Andrews e Chandler, até referências mais recentes, como Hamel e Prahalad, de acordo com duas perspectivas. Dentro da visão determinística, o ambiente é descrito como sendo completamente distinto e separado da organização, existindo claras fronteiras, que delimitam a ambos. Na visão indeterminista, conceptualiza-se a idéia de que a organização e o ambiente não são completamente separados e independentes, mas que pertencem ao mesmo continuum. Os resultados encontrados, a partir de uma análise de artigos apresentados no ENANPAD, apontam a predominância de uma visão determinística do ambiente, em que Porter é um dos autores mais citados. A visão indeterminista do ambiente aparece como uma perspectiva que ainda atrai poucos pesquisadores. A diminuta citação de autores nacionais é outro aspecto relevante da análise feita, refletindo a limitação da pesquisa acadêmica brasileira nesta área de conhecimento.

Palavras-chaves: estratégia; determinismo ambiental; indeterminismo.

\section{Abstract}

This article analyzes the dominant approaches in the Brazilian studies on strategy. We used a theoretical framework that classifies the main authors in strategy from the classics, such as Andrews, to more recent ones, as Hamel and Prahalad. We classified them into two perspectives. The deterministic view considers the external environment completely distinct and separated from the organization, existing clear boundaries delimiting both. According to the indeterministic view, organization and external environment are not completely separated and independent, but they belong to a continuum. The results are based on the articles presented in the ENANPAD conference from 1997 to 2001, and they point out a predominance of the deterministic view, whose Porter is the most referenced author. The indeterministic view still attracts a few researchers. The small number of Brazilian authors referenced is another relevant finding, showing an unknowingness of the own Brazilian researchers on Brazilian studies in strategy.

Key words: strategy; environmental determinism; indeterminism. 


\section{INTRODUÇÃO}

A introdução do conceito de organização como sistema aberto, derivado dos trabalhos de Bertalanffy (1950), aportou aos estudos organizacionais uma nova perspectiva: a necessidade de se analisarem as políticas e ações empreendidas pelos tomadores de decisão para fazer face à influência do meio ambiente externo sobre as organizações. Se a concepção de sistema fechado envolvia estudos fundamentados nas regras de pura racionalidade, a visão de sistema aberto implicava a necessidade de descrever estratégias que considerassem a incerteza criada no exterior da organização (Thompson, 1967).

A descrição do ambiente externo suscitou o aparecimento de duas visões distintas sobre a natureza desse ambiente. Na primeira delas, a organização difere em termos de funções, propriedades estruturais e objetivos - de mercados, clientes, fornecedores, competidores e instituições. Os tomadores de decisão, segundo essa perspectiva, são descritos como estando à mercê das mudanças e das ameaças ambientais e suas ações como dirigidas a enfrentar as forças externas. Essa visão poderia ser classificada como determinista, pois os tomadores de decisão aceitam o ambiente externo como dado e imutável e atuam internamente para compensar as influências externas.

A segunda visão, descrita aqui como indeterminista, conceptualiza a idéia de que a organização e o ambiente não são completamente separados e independentes, mas que pertencem ao mesmo continuum. Organização e ambiente estão interligados e, se é possível contemplar a influência do contexto externo sobre os atores organizacionais, é possível, também, considerar a influência da organização sobre o ambiente. A organização, dirigida por seus tomadores de decisão, não é tida como ator passivo: ela pode, também, influenciar, mudar e até estruturar o ambiente.

As concepções determinista e indeterminista, como consideradas aqui, portanto descrevem diferentes percepções do ambiente, que resultam no entendimento de diferentes atitudes e ações dos atores organizacionais com relação a suas ações estratégicas. Se a percepção do ambiente é determinista, a estratégia será descrita como direcionada a ações que tentam fazer face às influências externas. Se a percepção do ambiente é indeterminista, a estratégia será entendida como vinculada a ações de modificação e construção do ambiente externo.

É importante enfatizar que a estratégia é aqui entendida como processo assu- 
mido pelos tomadores de decisão, isto é, pelos atores localizados no topo da organização. A estratégia, como tal, se caracteriza por distintos padrões de ação e depende de como os tomadores de decisão percebem o ambiente e interagem com atores externos. Esse entendimento da estratégia - como processo e não como conteúdo - aproxima-se da definição de Mintzberg (1978, p. 935), que a conceitua como "decisões num fluxo de ações".

A discussão proposta a seguir procura classificar os padrões de ação segundo a perspectiva determinista e indeterminista e pretende analisar como os autores brasileiros de estratégia e de estudos organizacionais se inserem nessas perspectivas. Para tanto foram analisados os anais do principal fórum nacional de discussões, os encontros da Associação Nacional dos Programas de Pós-Graduação em Administração (ANPAD), e estudados individualmente os artigos classificados nas áreas de Organizações/Estratégia e Administração Estratégica ${ }^{(1)}$.

\section{A Estratégia na Perspectiva Determinista}

A visão determinista considera o ambiente como externo e dado. As forças de influência são direcionadas do ambiente para a organização. Nesse sentido, as ações estratégicas descritas se voltam para a sobrevivência da organização mediante a busca interna de maior eficiência e de melhor desempenho. A literatura identifica diferentes padrões de ação adotados pelos tomadores de decisão que revelam diferentes atitudes e percepções em face do ambiente externo. Embora outras alternativas pudessem ser arroladas, os padrões de ação, aqui descritos de acordo com uma perspectiva determinista, são reunidos em quatro tipos distintos: inação/acomodação, seleção/adequação, amortecimento/redução de influência e adaptação/intervenção (Bignetti, 1999).

Inação/acomodação é um padrão caracterizado por uma atitude de indiferença com relação ao meio externo, pois os atores organizacionais percebem o ambiente como plácido e randômico (Emery e Trist, 1963), no qual a estabilidade é predominante. A sobrevivência é buscada por meio de ações que maximizem a eficiência e o lucro. As ações dos tomadores de decisão em geral são de natureza tática, e as mudanças organizacionais por eles conduzidas são incrementais. A literatura que descreve essas ações é derivada essencialmente de uma visão da organização como sistema fechado, isolado dos contextos histórico, social, institucional, político e econômico.

Os estudos de Taylor (1911), Fayol (1916) e da burocracia de Weber (1947) são exemplos de abordagens dedicadas à busca da eficiência interna e da racionalidade. 
A perspectiva de sistema fechado é também adotada por autores como Barnard (1938), Roethlisberger e Dickson (1939), Mayo (1945) e Simon (1976).

Seleção/adequação é um padrão de ações adotado por atores organizacionais que percebem o ambiente natural como capaz de selecionar a organização mais apta ou mais adequada a sobreviver no meio externo. O ambiente é entendido como povoado por organizações que competem entre si pela sobrevivência. A atitude perante esse ambiente natural de seleção é essencialmente passiva e as ações empreendidas pelos tomadores de decisão consistem em desenvolver um processo cumulativo de aprendizagem e em criar uma contínua agregação de experiências. Os tomadores de decisão aceitam as imposições externas e se consideram limitados no poder de influenciar o processo de seleção.

O suporte teórico para esse padrão de ações pode ser encontrado na ecologia das populações (Hannan e Freeman, 1977; Aldrich, 1979) e, até certo ponto, na economia evolucionista (Nelson e Winter, 1982). De acordo com a ecologia das populações, a diversidade das formas organizacionais pode ser explicada pelo equilíbrio existente entre formas perfeitamente adaptadas ao meio. As organizações sobreviventes são selecionadas por meio de um processo determinístico de variação, seleção e retenção, sobre o qual a organização não exerce nenhum controle. A economia evolucionista se baseia em três idéias básicas: rotinas organizacionais, busca e ambiente de seleção. Na analogia com estudos biológicos, as rotinas seriam os genes e a busca seria responsável pelas mutações.

Amortecimento/redução de influência é um padrão que caracteriza as ações dos tomadores de decisão no sentido de absorver os choques externos e amortecer as influências vindas do ambiente. Thompson (1967) descreve as ações empreendidas pela organização para proteger seu core técnico com componentes de output e de input, por exemplo por meio da estocagem interna de materiais ou da implantação de depósitos em trânsito ou em distribuidores. As ações de redução de influência por parte dos tomadores de decisão concentram-se na alocação interna de recursos para fazer frente à escassez ambiental.

Do ponto de vista teórico, a teoria da dependência de recursos parece ser uma abordagem adequada para descrever ações de redução de influência (Meznar e Nigh, 1995). A teoria da dependência dos recursos (Pfeffer e Salancik, 1978) assinala a importância crítica que os recursos possuem para a sobrevivência da organização. Recursos escassos estão disponíveis no ambiente, e a organização interage com aqueles que possuem ou dominam as fontes de recursos. Sendo a organização dependente de elementos contidos no ambiente de tarefa na proporção direta da importância desses elementos para o seu desempenho (Thompson, 1967), a escassez de recursos externos se reflete no processo interno da alocação 
desses recursos. Mudanças organizacionais, portanto, são limitadas ou induzidas pela disponibilidade de recursos.

Adaptação/intervenção pode ser entendido como o padrão de ações em que os tomadores de decisão percebem a organização como vinculada ao ambiente externo e como reativa a influências desse ambiente. Numa extensiva descrição das organizações como sistemas adaptativos, Cyert e March (1992) consideram que fontes externas de perturbação e decisões internas são responsáveis pelas mudanças organizacionais. Atores organizacionais promovem o design das estratégias de ajuste às ameaças ambientais.

Adaptação/intervenção caracteriza um padrão de ações que pode ser considerado como determinista com respeito à percepção de um ambiente externo e dado, mas, ao mesmo tempo, como voluntarista com relação ao papel mais ativo atribuído aos tomadores de decisão. De fato, escolhas estratégicas (Child, 1972) e determinismo não são mutuamente excludentes. Segundo Thompson (1966, p. 78), "variáveis controladas pela organização estão subordinadas às restrições e contingências das quais elas não podem escapar"; entretanto "as organizações não são simplesmente determinadas pelo seu ambiente. As administrações podem inovar em muitas ou em todas as dimensões necessárias, mas apenas na extensão em que as inovações são aceitáveis por aqueles de quem a organização pode e deve depender" (Thompson, 1978, p. 148).

Pela amplitude das diferentes possibilidades de ações estratégicas que se enquadram nesse padrão, adaptação/intervenção é talvez o padrão de ações mais contemplado na literatura tradicional de estratégia. Em geral, a formulação estratégica pela adaptação ao meio externo é postulada pelas abordagens racionais da administração estratégica. As visões clássicas da estratégia, especialmente aquelas denominadas por Mintzberg (1990) de escolas prescritivas, como planificação (Ansoff, 1965), posicionamento (Porter, 1980, 1985) e design (Andrews, 1975) são as mais representativas do modelo adaptativo.

Os quatro padrões de ações acima descritos, de acordo com uma perspectiva determinista, representam uma seqüência de ações que se deslocam de um papel passivo até um papel mais ativo. Nesse sentido, há crescente ênfase em escolhas estratégicas e em mudanças organizacionais de uma extremidade do continuum a outra. A apresentação dos padrões de ações, entretanto, não se restringe aos quatro modelos apresentados. Torna-se necessário analisar, também, a maneira como, de uma perspectiva indeterminista, os padrões podem ser descritos. Essa é a discussão apresentada a seguir. 


\section{A Estratégia na Perspectiva Indeterminista}

A descrição da estratégia segundo uma visão determinista pressupõe que os tomadores de decisão possuem limitados graus de liberdade, atuam fundamentalmente dentro dos domínios organizacionais e são influenciados pelas ameaças e restrições ambientais. Como afirma Zucker (1983, p. 3), “o papel da organização é minimizado: a ênfase está mais nas forças que afetam a organização do que nas forças que são afetadas pela organização”. Em outras palavras, se há organizações que são influenciadas, é possível antever a existência de organizações que influenciam.

A perspectiva indeterminista introduz a idéia de volição, de influência e de construção num ambiente em que ocorrem processos não-lineares e dependentes da trajetória. Não há fronteiras definidas que separem organização e ambiente. Os atores organizacionais influenciam e são influenciados pelo meio e induzem a organização a provocar ou a imediatamente assumir as rápidas transformações de mercado, de tecnologia e de regras competitivas. Os padrões de ações adotados, portanto, se caracterizam por atitudes essencialmente interativas por parte dos tomadores de decisão. Assim, dentro de uma abordagem indeterminista, dois padrões serão discutidos a seguir: influência/compromisso e modificação/construção.

Influência/compromisso é um padrão de ações que pressupõe a existência de um ambiente que afeta a organização, mas atribui aos tomadores de decisão o poder de introduzir modificações no ambiente, especialmente por meio de compromissos assumidos com outras organizações e instituições que regulem as relações interorganizacionais (Oliver, 1990). Uma ordem negociada estabelece os termos sob os quais a organização poderá interagir com outras. Essa ordem, no entanto, é fluida e se modifica de acordo com mudanças e acontecimentos que ocorrem entre ela e o ambiente (Nathan e Mitroff, 1991). A atitude dos atores pode ser tanto defensiva como ofensiva, dependendo do poder relativo da organização. Em todo o caso, existe a percepção de ser possível a modificação das regras e das relações de modo a garantir a continuidade organizacional.

Influência/compromisso vincula-se, portanto, à escola de poder (Mintzberg, 1990), à perspectiva institucionalista (Zucker, 1987) e à abordagem dos stakeholders (Freeman, 1984). A escola de poder pressupõe que a estratégia se desenvolve segundo um processo de negociação em que coexistem conflitos e coalizões que refletem interesses dos atores internos e externos (Allison, 1971; Perrow, 1986). A escola institucionalista baseia-se em dois aspectos teóricos básicos: a organização como instituição indica que o foco central está na criação 
de significado (o processo de geração) dentro da organização; e o ambiente como instituição indica que a questão fundamental é a reprodução dos atos sociais no nível organizacional. O conceito de stakeholder aborda a existência de indivíduos ou grupos que afetam a organização ou são afetados por ela. Influência/compromisso introduz na discussão sobre estratégia um novo vetor, agora dirigido da organização em direção ao ambiente. Este vetor indica o grau de influência da organização sobre o contexto externo e pressupõe maior vinculação entre atores internos e externos.

O último padrão de ações a ser considerado é modificação/construção. Este padrão se caracteriza pelo entendimento de que atores organizacionais são capazes de modificar cursos de ação e de criar novas e únicas oportunidades externas. Os tomadores de decisão são considerados como promotores de mudanças tecnológicas, criadores de novos mercados e, até, formadores de novos setores industriais. A atitude dos tomadores de decisão é essencialmente proativa e destinada a construir o ambiente externo. Hamel e Prahalad (1994), por exemplo, discutem as limitações de estratégias como downsizing e reengenharia (baseadas numa visão determinista do ambiente) e defendem uma atitude mais proativa dos dirigentes, argumentando que as empresas devem reinventar setores industriais e regenerar estratégias, criando o futuro.

Para chegar ao futuro, os tomadores de decisão criam core competences, habilidades e tecnologias que possibilitam à organização modificar o ambiente e criar novas regras competitivas por meio da formação de alianças e coalizões com parceiros e, até, com competidores. A estratégia é concebida, não como plano, mas como processo dinâmico, de constante interação com atores externos. A lógica individualista é substituída por uma lógica de busca de parceiros para repartir o risco, reduzir custos, criar mercados e obter retornos crescentes de adoção (Bignetti, 1999).

Abordagens teóricas recentes, especialmente vinculadas ao estudo de empresas intensivas em conhecimento, procuram retratar as ações de construção de ambientes e de mercados na forma como concebidas pelos tomadores de decisão. Esta visão da estratégia como socialmente construída pela interação de atores internos e externos se baseia em premissas da escola cognitiva (Weick, 1979, 1995), na economia de feedbacks positivos (Arthur, 1996) e no construtivismo social da estratégia e da tecnologia (Rouleau, 1995; Bijker, Hughes e Pinch, 1997; Bignetti, 2000).

A concepção da estratégia como padrão de ações possibilitou a descrição de uma variedade de padrões, que encontram na literatura de estudos organizacionais e de estratégia uma ampla descrição, dentro da perspectiva determinista e 
indeterminista. O Quadro 1 resume as principais colocações feitas até aqui, descrevendo as possíveis relações dos tomadores de decisão com o ambiente, as suas atitudes estratégicas e as percepções que possuem do ambiente. Identifica, também, as escolas de estratégia e de estudos organizacionais e os principais autores que poderiam ser relacionados a cada padrão de ações.

\section{Quadro 1: Escolas de Pensamento que se Vinculam a Padrões de Ações segundo as Perspectivas Determinista e Indeterminista}

\begin{tabular}{|c|c|c|c|c|c|}
\hline $\begin{array}{l}\text { Padrão de } \\
\text { ações }\end{array}$ & $\begin{array}{c}\text { Relação com o } \\
\text { ambiente }\end{array}$ & Atitude & $\begin{array}{c}\text { Percepção } \\
\text { do } \\
\text { ambiente } \\
\end{array}$ & $\begin{array}{c}\text { Escola } \\
\text { organizacional } \\
\text { e de estratégia } \\
\end{array}$ & Autores \\
\hline $\begin{array}{l}\text { Inação/ } \\
\text { Acomodação }\end{array}$ & $\begin{array}{l}\text { Equilíbrio } \\
\text { Harmonia } \\
\text { Congruência }\end{array}$ & Inativa & $\begin{array}{l}\text { Determi- } \\
\text { nismo }\end{array}$ & Clássica & $\begin{array}{l}\text { Taylor } \\
\text { Barnard } \\
\text { Simon }\end{array}$ \\
\hline $\begin{array}{l}\text { Seleção/ } \\
\text { Adequação }\end{array}$ & $\begin{array}{l}\text { Conformidade } \\
\text { ser selecionado } \\
\text { Evolução }\end{array}$ & Passiva & $\begin{array}{l}\text { Determi- } \\
\text { nismo }\end{array}$ & $\begin{array}{l}\text { Ecologia das } \\
\text { Populações } \\
\text { T. Evolucionista } \\
\text { Contingencial }\end{array}$ & $\begin{array}{l}\text { Hannan e Freeman } \\
\text { Aldrich } \\
\text { Nelson e Winter } \\
\text { Chandler }\end{array}$ \\
\hline $\begin{array}{l}\text { Amortecim./ } \\
\text { Redução de } \\
\text { influência }\end{array}$ & $\begin{array}{l}\text { Estabilização } \\
\text { Absorção } \\
\text { Abrandamento }\end{array}$ & Reativa & $\begin{array}{l}\text { Determi- } \\
\text { nismo }\end{array}$ & $\begin{array}{l}\text { Dependência de } \\
\text { Recursos }\end{array}$ & Pfeffer e Salancik \\
\hline $\begin{array}{l}\text { Adaptação/ } \\
\text { Intervenção }\end{array}$ & $\begin{array}{l}\text { Ajustamento } \\
\text { Enfrentamento } \\
\text { Interferência }\end{array}$ & $\begin{array}{l}\text { Ativa } \\
\text { (defensiva } \\
\text { e ofensiva) }\end{array}$ & $\begin{array}{l}\text { Determi- } \\
\text { nismo }\end{array}$ & $\begin{array}{l}\text { Planificação } \\
\text { Design } \\
\text { Posicionamento } \\
\text { Balanced Scorecard } \\
\text { Configuracional } \\
\text { Estratégia e } \\
\text { Estrutura }\end{array}$ & $\begin{array}{l}\text { Ansoff, Selznick, } \\
\text { Porter, Miles e } \\
\text { Snow, Andrews, } \\
\text { Mintzberg, Quinn, } \\
\text { Schendel, Teece, } \\
\text { Kaplan e Norton }\end{array}$ \\
\hline $\begin{array}{l}\text { Influência/ } \\
\text { Compromisso }\end{array}$ & $\begin{array}{l}\text { Atuação } \\
\text { política } \\
\text { Ordem } \\
\text { negociada }\end{array}$ & $\begin{array}{l}\text { Interativa } \\
\text { (defensiva } \\
\text { e ofensiva) }\end{array}$ & $\begin{array}{l}\text { Indetermi- } \\
\text { nismo }\end{array}$ & $\begin{array}{l}\text { Poder } \\
\text { Institucionalismo } \\
\text { Stakeholder } \\
\text { Teoria dos Jogos }\end{array}$ & $\begin{array}{l}\text { Perrow } \\
\text { Allison } \\
\text { Freeman } \\
\text { Von Neumann }\end{array}$ \\
\hline $\begin{array}{l}\text { Modificação/ } \\
\text { Construção }\end{array}$ & $\begin{array}{l}\text { Cooperação- } \\
\text { Competição } \\
\text { Criação }\end{array}$ & $\begin{array}{l}\text { Interativa } \\
\text { (Proativa) }\end{array}$ & $\begin{array}{l}\text { Indetermi- } \\
\text { nismo }\end{array}$ & $\begin{array}{l}\text { Cognitivismo } \\
\text { Construtivismo } \\
\text { Resource-Based } \\
\text { Alianças } \\
\text { Estratégicas }\end{array}$ & $\begin{array}{l}\text { Weick } \\
\text { Hughes } \\
\text { Hamel, Prahalad } \\
\text { Doz }\end{array}$ \\
\hline
\end{tabular}

Fonte: adaptado de Bignetti (1999).

Como se observa no quadro, a classificação proposta torna possível a identificação dos autores vinculados aos estudos de estratégia e à forma como eles se relacionam com os padrões de ações estabelecidos na presente discussão. A seguir, utilizando-se a mesma classificação como base, propõe-se uma análise da literatura brasileira de estratégia e da vinculação dos pesquisadores brasileiros com os diferentes padrões de ações estabelecidos na discussão anterior. 


\section{A Literatura Brasileira de Estratégia e os Padrões de Ações}

Uma vez que as principais escolas de estratégia foram identificadas de acordo com a classificação proposta de padrões de ações, procura-se, agora, proceder a uma análise preliminar das citações dos autores representativos de cada escola nos trabalhos apresentados no Encontro Anual da Associação Nacional dos Programas de Pós-Graduação em Administração (ENANPAD). O ENANPAD reúne anualmente muitos dos principais pesquisadores brasileiros de Administração, especialmente aqueles vinculados a programas de pós-graduação, sendo um fórum de debates que congrega trabalhos indicativos do estado da arte em gestão no Brasil.

Para a realização, cujos resultados são aqui discutidos em termos de autores estrangeiros e autores nacionais, foram analisados os trabalhos apresentados nos últimos cinco anos, isto é, nos encontros de 1997 a 2001, num total de 185 trabalhos. Os anais do ENANPAD de cada ano registram o grau de seletividade do encontro. Assim, em 1997, dos 91 trabalhos submetidos, foram selecionados 28; em 1998, foram 118 trabalhos submetidos e 31 selecionados; em 1999, foram apresentados 100 trabalhos e selecionados 30; em 2000 dos 124 apresentados, 38 foram selecionados, e, finalmente, em 2001 foram apresentados 160 trabalhos e selecionados 58. Embora os trabalhos fossem enquadrados dentro da área de estratégia, alguns deles apenas tangencialmente poderiam ser classificados como tais; entretanto foi respeitado o enquadramento a que procedeu a comissão de seleção.

\section{Análise das Citações de Autores Estrangeiros}

Numa primeira etapa dos estudos, o conjunto dos trabalhos foi analisado de acordo com a classificação proposta no Quadro 1, que classifica os autores representativos da literatura internacional de acordo com os padrões de ação. Para cada artigo, foram listados os autores predominantemente citados, a adoção do conceito de estratégia como conteúdo ou como processo, a percepção do ambiente externo como determinista ou indeterminista, e a estratégia como padrões de ações, variando dentro do espectro de inação/acomodação a modificação/ construção.

A análise preliminar dos dados requereu algumas simplificações. Em primeiro lugar, nos casos em que dois ou mais autores eram citados ou discutidos no referencial teórico, optou-se por escolher aqueles que eram predominantes na discussão. Em segundo lugar, alguns trabalhos limitavam-se a uma comparação entre abordagens. Quando os autores do trabalho não se posicionavam critica- 
mente com relação a elas, foram referenciados os autores principais de cada abordagem. Em terceiro lugar, em alguns trabalhos a análise foi dificultada, seja pela omissão de um quadro conceitual claro, seja pela pouca vinculação com a área de estratégia. Esses trabalhos foram total ou parcialmente desconsiderados.

A Tabela 1 apresenta o resultado da análise dos artigos com relação à percepção do ambiente na forma como se apresenta no artigo. Foram classificadas como deterministas aquelas abordagens teóricas que apresentavam o ambiente externo como dado e independente da organização e que descreviam a estratégia como resposta às incertezas ambientais. Foram classificadas como indeterministas aquelas abordagens que descreviam ou prescreviam ações para modificar o ambiente e, por exemplo, criar novos mercados.

\section{Tabela 1: A Percepção do Ambiente nas Abordagens Teóricas: Trabalhos Classificados segundo as Perspectivas}

\begin{tabular}{cc}
\hline $\begin{array}{c}\text { Perspectiva determinista } \\
\text { do ambiente }\end{array}$ & $\begin{array}{c}\text { Perspectiva indeterminista } \\
\text { do ambiente }\end{array}$ \\
\hline 126 trabalhos & 49 trabalhos \\
\hline
\end{tabular}

Fonte: dados coletados do ENANPAD.

Como se observa, os pesquisadores brasileiros referenciados no ENANPAD adotaram nos últimos anos autores que descrevem o ambiente segundo uma perspectiva predominantemente determinista: mais de $70 \%$ dos trabalhos analisados apresentavam uma abordagem teórica que identificava um ambiente externo dado e descreviam estratégias que poderiam ser classificadas como deterministas. De fato, os resultados indicam que os pesquisadores se concentram no processo de planejamento estratégico, nas estratégias de posicionamento no mercado e nas ações empreendidas pela empresa, para fazer face às incertezas ambientais, especialmente pelo estabelecimento de estratégias de adaptação às ameaças ambientais.

Quando detalhada a perspectiva determinista e indeterminista em padrões de ações estratégicas, verifica-se que predominam aqueles padrões de ações que enfatizam a adaptação ao meio ambiente. A Tabela 2 resume a classificação dos trabalhos de acordo com os padrões de ações descritos nos trabalhos analisados segundo a perspectiva determinista. 
Tabela 2: A Incidência nos Trabalhos dos Padrões de Ações Apoiados pela Perspectiva Determinista

\begin{tabular}{lc}
\hline Padrões de ações & Incidência (no. de trabalhos) \\
\hline Inação/acomodação & 8 \\
Seleção/adequação & 15 \\
Amortecim./red. influência & 1 \\
Adaptação/intervenção & 102 \\
\hline
\end{tabular}

Fonte: dados coletados do ENANPAD.

Quando considerada a opção dos pesquisadores nas abordagens teóricas, verifica-se que a maior parte dos trabalhos poderia ser classificada dentro do padrão de ações definido como adaptação/intervenção. De fato, os pesquisadores brasileiros que apresentaram trabalhos no ENANPAD dos quatro últimos anos preferentemente se inclinam por uma abordagem teórica que poderia ser classificada dentro de uma das três escolas tidas por Mintzberg (1990) como prescritivas: design, planificação e posicionamento. Os trabalhos que se enquadram nessa classificação descrevem quatro processos distintos: a concepção estratégica, a formalização estratégica, a análise estratégica e o controle estratégico.

A escola predominante entre os trabalhos apresentados de acordo com o padrão adaptação/intervenção é a escola de posicionamento, que favorece a escolha de posições estratégicas no mercado em busca de vantagens competitivas específicas. Ressalta-se, aqui, a preponderância dos estudos que adotam a cadeia de valor e as estratégias de diferenciação e de custos, na forma preconizada por Porter $(1980,1985)$. Alguns dos trabalhos revisitados, em realidade adotam exclusivamente uma abordagem setorial e de posicionamento num mercado específico, segundo uma lógica baseada na economia industrial. Identifica-se, portanto, uma nítida opção dos pesquisadores brasileiros pela descrição da estratégia como conteúdo, e não como processo.

Guardando a segunda posição entre os trabalhos analisados, seleção/adequação representa um padrão bem menos referenciado, mas que merece destaque pelas abordagens evolucionista e contingencial, que aparecem em alguns dos referenciais teóricos. Do lado evolucionista, enquadram-se trabalhos que se referem à seleção dos mais aptos por parte do meio ambiente. Do lado da contingência, há referências aos trabalhos de Chandler (1962), especialmente com relação à causalidade estratégia/estrutura.

No que concerne à perspectiva indeterminista, embora seja relativamente menos referenciada que a visão determinista, possui ela relativa relevância, especialmente 
para os pesquisadores que descrevem a vinculação da organização ao meio ambiente. A Tabela 3 indica a preferência relativa dos pesquisadores brasileiros do ENANPAD com relação aos padrões de influência/compromisso e modificação/construção.

\section{Tabela 3: A Opção pelos Padrões de Ações segundo a Percepção Indeterminista}

\begin{tabular}{lc}
\hline Padrões de ações & Incidência (no. de trabalhos) \\
\hline Influência/compromisso & 14 \\
Modificação/construção & 35 \\
\hline
\end{tabular}

Fonte: dados coletados do ENANPAD.

Modificação/construção representa, dentro da perspectiva indeterminista, o padrão de ações mais referenciado. Alguns artigos tratam de forma especial dos modelos competitivos e das considerações prescritivas de Hamel e Prahalad (1994) de construção de mercados e de delineamento do futuro. No que diz respeito à influência/compromisso, a referência principal se dá à análise da influência política e ao poder atribuído aos tomadores de decisão.

Uma análise preliminar dos autores referenciados reafirma as preferências dos pesquisadores brasileiros pelas escolas clássicas de estratégia. A Tabela 4 classifica os autores mais citados nos referenciais teóricos dos 185 trabalhos analisados. Embora outros autores tenham sido citados, apenas os mais vezes referenciados constam da tabela.

Dentro de uma perspectiva determinista, Porter é o autor dominante e recorrentemente citado por pesquisadores brasileiros nos trabalhos apresentados no ENANPAD. O modelo de Porter de análise competitiva é empregado, por exemplo, para a identificação das forças ambientais que influenciam a concorrência das empresas e para a análise da competitividade de empresas de diversos portes e dos mais variados setores industriais e de serviços. Referências a Porter são também feitas na discussão da cadeia de valor, no estudo ou no estabelecimento de estratégias de posicionamento e na análise de clusters industriais.

O segundo autor mais citado nos trabalhos é Mintzberg, pois tanto aparece como referência em estudos organizacionais como em estratégia. As referências à obra de Mintzberg são, do grupo representativo de autores, aquelas que possuem mais amplitude. Em alguns casos, Mintzberg é citado por sua contribuição aos estudos organizacionais, especialmente com relação às suas configurações de estrutura e poder. Em outros, é referenciado por sua contribuição ao entendi- 
mento da estratégia como processo emergente de transformação. Mintzberg é também citado por sua classificação do campo dos estudos de estratégia em dez escolas.

Tabela 4: Os Autores Mais Citados

\begin{tabular}{lcccccc}
\hline Autor & Ano & Ano & Ano & Ano & Ano & Total \\
& 1997 & 1998 & 1999 & 2000 & 2001 & \\
\hline Porter & 16 & 28 & 15 & 16 & 15 & 90 \\
Mintzberg & 10 & 19 & 9 & 20 & 10 & 68 \\
Hamel e Prahalad & 12 & 7 & 8 & 7 & 6 & 40 \\
Ansoff & 10 & 11 & 5 & 10 & 2 & 38 \\
Chandler & 2 & 4 & 8 & 7 & 2 & 22 \\
Miles e Snow & 3 & 4 & 8 & 4 & 3 & 22 \\
Kaplan e Norton & 1 & - & 3 & 7 & 5 & 16 \\
Quinn & - & 4 & 2 & 5 & 2 & 13 \\
Drucker & 2 & 3 & 3 & 2 & 1 & 11 \\
Freeman & 1 & 2 & 2 & 4 & 2 & 11 \\
Kotler & 3 & 4 & - & 3 & 1 & 11 \\
Schein & 1 & 6 & 2 & 1 & 2 & 11 \\
Rumelt e Schendel & - & 2 & 2 & 3 & 3 & 10 \\
Teece & - & 1 & 3 & 3 & 2 & 9 \\
Andrews & - & 1 & 5 & - & 1 & 7 \\
Collins e Porras & - & - & 2 & 4 & 1 & 7 \\
Selznick & - & - & 2 & 1 & - & 3 \\
\hline
\end{tabular}

Fonte: dados coletados do ENANPAD.

Ainda de acordo com uma visão determinista da estratégia, o terceiro autor mais citado - e quarto na classificação geral - é Ansoff, representante da escola de planificação. Os trabalhos analisados enfatizam o planejamento como processo formal de estabelecimento de objetivos e de fixação de programas de ação e de estratégias funcionais. Chandler, com seus estudos clássicos sobre estratégia e estrutura, e Miles e Snow, com sua descrição de estratégias genéricas e de padrões de comportamento estratégico, são autores também referenciados pelos pesquisadores nacionais.

Dentro de uma perspectiva indeterminista, Hamel e Prahalad são os autores mais citados. Os trabalhos analisados contemplam conceitos como core competence, visão baseada em recursos, tensão e alavancagem. Alguns deles referem-se à intenção estratégica, que proclama a busca da liderança através do estabelecimento de metas ambiciosas de liderança no mercado. 
A Tabela 4 relaciona ainda alguns outros autores estrangeiros citados nos artigos do ENANPAD. Embora cerca de trinta autores fossem considerados nesse estudo preliminar como relevantes, Porter, Mintzberg, Hamel e Prahalad, Ansoff, Chandler e Miles e Snow são os mais referenciados e são responsáveis pela maioria das menções.

Uma análise mais detalhada da tendência expressa pelos pesquisadores brasileiros revela alguns aspectos interessantes. Em primeiro lugar, há predominância, em alguns anos, de referências a determinadas obras traduzidas para o português, que caracterizam certo modismo. Por exemplo, Hamel e Prahalad (1995), autores dos mais referenciados, são citados principalmente pelo livro Competindo pelo Futuro; Collins e Porras (1998) por Feitas para Durar; Ghemawat (2000) por A Estratégia e o Cenário dos Negócios; e Mintzbergh, Ahlstrand e Lampel (2000) por Safári da Estratégia.

Em segundo lugar, verifica-se que alguns assuntos vêm despontando de forma especial nos últimos anos. Assim, a gestão do conhecimento, a visão baseada em recursos, as competências distintivas e o balanced scorecard são alguns dos assuntos preferentemente citados nos referenciais teóricos dos artigos, trazendo para a discussão autores como Nonaka e Takeushi, Leonard-Barton, Wernerfelt, Kaplan e Norton, entre outros.

Em terceiro lugar, há um predomínio anglo-saxão indiscutível. Os autores norte-americanos, especialmente, têm merecido de parte dos pesquisadores brasileiros um crédito muito maior do que autores nacionais. A dependência dos aportes teóricos externos fica evidente, quando se analisam as citações feitas dos autores nacionais, como a seguir se evidencia.

\section{Análise das Citações de Autores Nacionais}

Além dos autores tradicionais de estratégia foram analisadas as citações de autores brasileiros. É forçoso salientar a ainda reduzida participação de autores nacionais entre os citados. Os pesquisadores brasileiros pouco conhecem sobre a produção teórica nacional no campo da estratégia. A Tabela 5 apresenta os dez pesquisadores brasileiros mais referenciados nos trabalhos apresentados no ENANPAD no período de 1997 a 2001.

Alguns dos aspectos identificados nas citações de autores estrangeiros de alguma forma se repetem aqui. Vários dos autores mais citados seguem uma abordagem determinista dentro de um enfoque de planificação derivada de Ansoff, incluindo-se neste caso Fischmann e Almeida, Oliveira e alguns trabalhos de Zaccarelli. 
Tabela 5: Os Autores Nacionais Mais Citados

\begin{tabular}{lcccccc}
\hline Autor & $\begin{array}{c}\text { Ano } \\
\text { 1997 }\end{array}$ & $\begin{array}{c}\text { Ano } \\
1998\end{array}$ & $\begin{array}{c}\text { Ano } \\
1999\end{array}$ & $\begin{array}{c}\text { Ano } \\
2000\end{array}$ & $\begin{array}{c}\text { Ano } \\
2001\end{array}$ & Total \\
\hline Fischmann e Almeida & 5 & 4 & - & - & 1 & 10 \\
Machado-da-Silva & 3 & - & 3 & 2 & 1 & 9 \\
Oliveira & - & 3 & - & 3 & 3 & 9 \\
Zaccarelli & 3 & 1 & - & - & 5 & 9 \\
Coutinho e Ferraz & 2 & 2 & - & 1 & 3 & 8 \\
Fleury & 1 & 3 & - & 1 & 3 & 8 \\
Gimenez & 2 & - & 1 & - & 4 & 7 \\
Cabral & - & 1 & 3 & - & 2 & 6 \\
Wood Jr. & 3 & - & 1 & - & 2 & 6 \\
Motta & 1 & - & 1 & 3 & - & 5 \\
TOTAL & 20 & 14 & 9 & 11 & 24 & 78 \\
\hline
\end{tabular}

Fonte: dados coletados do ENANPAD.

Os que mais se aproximam de uma abordagem indeterminista são aqueles que de certo modo seguem enfoques relativos à visão baseada em recursos e competetências internas como Fleury.

Alguns autores, como Machado-da-Silva, possuem trabalhos que ora estão mais próximos da abordagem determinista, como, por exemplo, quando aborda questões referentes à configuração organizacional, e ora aproximam-se de um enfoque indeterminista, como, por exemplo, quando aborda questões relativas a estratégia, cultura e poder.

Também no caso de citações de autores brasileiros é possível identificar uma presença marcante de referências a livros como Fischmann e Almeida (1991) Planejamento Estratégico na Prática; Oliveira (1991) - Planejamento Estratégico: Conceitos, Metodologia e Prática; Coutinho e Ferraz (1994) - Estudo da Competitividade da Indústria Brasileira; Zaccarelli (1996, 2000) - Estratégia Moderna nas Empresas e Estratégia e Sucesso nas Empresas; Fleury e Fleury (1997) - Aprendizagem e Inovação Empresarial: As Experiências de Japão, Coréia e Brasil; e Motta (1991) - Gestão Contemporânea: A Ciência e a Arte de Ser Dirigente. Este último ainda que não seja especificamente da área de estratégia foi incluído por tratar de um tema próximo, o papel do dirigente na empresa.

Outros autores como Machado-da-Silva, Gimenez, Cabral e Wood Jr. são citados quase exclusivamente por seus artigos apresentados nas diferentes edições do ENANPAD, o que reforça a importância deste como um fórum de integração dos autores nacionais. 
Por fim, ainda que se possa identificar algum acréscimo no número de citações destes dez autores nacionais mais citados, ainda deve ser considerado este número muito tímido, quando se compara com as citações de autores estrangeiros. A soma das citações brasileiras na Tabela 5 é inferior a citação total de um único autor estrangeiro como Porter.

Os modelos estrangeiros e muito especialmente anglo-saxônicos imperam na academia brasileira e ocultam esforços isolados de desenvolvimento de uma abordagem nacional mais adequada às condições competitivas do mercado brasileiro.

\section{Conclusão}

Este estudo preliminar, se ainda não permite posições conclusivas, aponta vários questionamentos que são relevantes não só para as pesquisas na área de estratégia, mas também para os estudos organizacionais. Uma primeira questão a levantar seria o porquê da predominância da visão determinística. Uma suposição inicial estaria vinculada à predominância de empresas de setores industriais relativamente estáveis, ligados a mercados pouco turbulentos e possuindo produtos de ciclos de vida mais longos.

Quando se analisa o número de trabalhos dentro da visão indeterminística, se poderia concluir que poderá haver um aumento de estudos dentro dessa perspectiva, especialmente em função da grande importância que adquirem setores industriais e de serviços intensivos em tecnologia. Além disso, a globalização crescente das empresas possivelmente irá requerer estudos de estratégias empresariais que lancem alguma luz aos desafios da busca de novas parcerias e de novos mercados.

Um consideração importante deveria ainda ser feita com relação aos estudos brasileiros de administração estratégica. Embora limitado a cinco anos e referindo-se aos trabalhos apresentados no ENANPAD - não levando em consideração, portanto, outros fóruns ou as revistas brasileiras - o estudo remete a uma profunda discussão das causas da pouca importância dada aos trabalhos e modelos desenvolvidos por pesquisadores brasileiros. Uma primeira causa seria uma posição preferentemente colonizada dos pesquisadores brasileiros em face dos estudos estrangeiros. Uma segunda causa a ser apontada se refere ao número relativamente pequeno de pesquisadores na área e à pouca possibilidade que possuem de ter dedicação exclusiva à pesquisa. Além disso, a pouca integração entre estes mesmos autores pode ser outra causa. É possível que a consolidação 
de novos cursos de mestrado e doutorado possibilitem um incremento nos estudos brasileiros de estratégia. De qualquer forma, estudos complementares e mais aprofundados poderão esclarecer alguns dos pontos ainda obscuros.

Nota

${ }^{1}$ Os autores agradecem a colaboração dos bolsistas de Iniciação Científica Bernardo Vicente Vieira Neves e Max Oderich.

Referências Bibliográficas

ALDRICH, H. E.

Organizations and environments. Englewood Cliffs, NJ: Prentice-Hall, 1979.

\section{ALLISON, G. T.}

Essence of decision: explaining the Cuban missile crisis. Boston, MA: Harper Collins Publishers, 1971.

ANDREWS, K. A.

The concept of corporate strategy. Homewood, Ill.: DowJones Irwin, 1971.

ANSOFF, H. I.

Corporate strategy: an analytical approach to business policy for growth and expansion. New York: McGraw-Hill, 1965.

ARTHUR, W. B.

Positive feedbacks in the economy. Scientific American, Feb. 1990. Increasing returns and the new world of business. Harvard
Business Review, July/Aug. 1996.

BARLETT, C. A.;

GHOSHAL, S.

Going global - lessons from late movers. Harvard Business

Review, Mar./Apr. 2000.

BARNARD, C.

The functions of the executive.

Cambridge, MA: Harvard University Press, 1938.

BERTALANFFY, L. V.

General system theory: foundations, development, applications. New York: George Braziller, 1950.

BIGNETTI, L. P.

An appreciation about innovation and strategy under uncertainty and indeterminacy. Montreal: École des Hautes Études Commerciales, 1997. 


\section{Strategic actions and innovation practices in knowledge-based industries.} Montreal, 1999. Thèse (Doctorat) - École des Hautes Études Commerciales.

A relação entre ações estratégicas e práticas de inovação: o caso de uma empresa intensiva em conhecimento. In: ENCONTRO ANUAL DA ANPAD, XXIV, 2000, Florianópolis. Anais... Florianópolis: ANPAD, 2000a. 1 CD-ROM.

The innovation process in the knowledge-based economy. In: L'ÉCONOMIE DU SAVOIR: ENJEUX ÉCONOMIQUES ET ENJEUX DE GESTION, 2000b, Montreal.

BIJKER, W. E.;

HUGHES, T.;

PINCH, T.

The social construction of technological systems. 6. ed. Cambridge, MA: The MIT Press, 1997.

\section{CHILD, J.}

Organization structure, environment and performance: the role of strategic choice. Sociology, v. 6, 1972.

COLLINS, J. C.;

PORRAS, J. I.

Feitas para durar: práticas bemsucedidas de empresas visionárias. Rio de Janeiro: Rocco, 1998.
COUTINHO, L.;

FERRAZ, J. C.

Estudo da competitividade da indústria brasileira. Campinas:

Papirus, 1994.

CYERT, R. M.;

MARCH, J. G.

A behavioral theory of the firm. Cambridge, MA: Blackwell Publishers, 1963.

EMERY, F. E.;

TRIST, E. L.

The causal texture of organizational environments. In: I N T E R N A T I O N A L CONGRESS OF PSYCHOLOGY, XVII, 1963, Washington, DC. Proceedings... Washington, DC: [s.n.], 1963.

FAYOL, H.

Administration industrielle et générale: prévoyance, commandement, coordination, contrôle. Bulletin de la Société de L’Industrie Minérale, Paris, 1916.

FISCHMANN, A.; ALMEIDA, M. I.

Planejamento estratégico na prática. São Paulo: Atlas, 1991.

FLEURY, A. F.; FLEURY, M. T.

Aprendizagem e inovação empresarial: as experiências de Japão, Coréia e Brasil. São Paulo: Atlas, 1997. 
FOXHALL, G.;

FAWN, J.

An evolutionary model of technological innovation as a strategic management process.

Technovation, v. 12, n. 3, 1992.

FREEMAN, R. E.

Strategic management: a stakeholder approach. Boston, MA: Pitman, 1984.

GHEMAWATT, P.

A estratégia e o cenário dos negócios. Porto Alegre: Bookman, 2000.

HAMEL, G.;

PRAHALAD, C. K.

Competing for the future: what drives your company's agenda. Harvard Business Review, July/Aug. 1994.

Competindo pelo futuro. Rio de Janeiro: Campus, 1995.

HANNAN, M. T.;

FREEMAN, J. H.

The population ecology of organizations. American Journal of Sociology, v. 82, Mar. 1977.

MAYO, E.

The social problems of an industrial civilization. Boston, MA: Harvard Business School, 1945.
MEZNAR, M. B.;

NIGH, D.

Buffer or bridge? Environmental and organizational determinants of public affairs activities in American firms. Academy of Management Journal, v. 38, n. 9, 1995.

MINTZBERG, $\mathrm{H}$.

Patterns in strategy formation. Management Science, v. 24, n. 9, May 1978.

Strategy formation: schools of thought. In: FREDERICKSON, J. W. (Ed.). Perspectives on strategic management. New York: Harper \& Row, 1990. p. 105-235.

MINTZBERG, H.; AHLSTRAND, B.;

LAMPEL, J.

Safári de estratégia: um roteiro pela selva do planejamento. Porto Alegre: Bookman, 2000.

MOTTA, P. R.

Gestão contemporânea: a ciência e a arte de ser dirigente. Rio de Janeiro: Record, 1991.

NATHAN, M.; MITROFF, I.

The use of negotiated order theory as a tool for the analysis and development of an interorganizational field. Journal of Applied Behavioral Science, v. 27, 1991. 
NELSON, R. N.;

WINTER, S. G.

An evolutionary theory of economic change. Cambridge, MA: Harvard University Press, 1982.

OLIVEIRA, D. P. R.

Planejamento estratégico: conceitos, metodologia e prática. São Paulo: Atlas, 1991.

\section{OLIVER, C.}

Determinants of interorganizational relationships: integration and future directions. Academy of Management Review, v. 15, n. 2, 1990.

\section{PERROW, C.}

Complex organizations: a critical essay. 3. ed. New York: Random House, 1986.

PFEFFER, J.;

SALANCIK, G. R.

The external control of organizations: a resource dependence perspective. New York: Harper \& Row, 1978.

PORTER, M. E.

\section{Competitive}

strategy: techniques for analyzing industries and competitors. New York: The Free Press, 1980.

\section{Competitive advantage:} creating and sustaining superior performance. New York: The Free Press, 1985.
ROETHLISBERGER, F. J.;

DICKSON, W. J.

Management and the worker.

Cambridge, MA: Harvard

University Press, 1939.

ROULEAU, L.

La structuration sociale de l'activité stratégique: le cas Irving Samuel/Jean-Claude Poitras. Montreal, 1995. Thèse (Doctorat) - École des Hautes Études Commerciales.

SIMON, H.

Administrative behavior: a study of decision-making processes in administrative organization. 3. ed. New York: The Free Press, 1976.

SMIRCICH, L.;

STUBBART, C.

Strategic management in an enacted world. Academy of Management Review, v. 10, n. 4, 1995.

TAYLOR, F. W.

Scientific management. New York: Harper, 1911.

THOMPSON, J. D.

Organizations in action: social science bases of administrative theory. New York: McGraw-Hill, 1967.

UTTERBACK, J. M.

Mastering the dynamics of innovation. Boston, MA: Harvard Business School Press, 1994. 
WEBER, M.

The theory of social and economic organization. In: HENDERSON, A. H.; PARSONS, T. New York: The Free Press, 1947.

WEICK, K.

The social psychology of organizing. Reading, MA: Addison-Wesley, 1979.

Sensemaking in organizations. London: Sage Publications, 1995.

\section{WILLIAMS, R.;}

EDGE, D.

The social shaping of technology: research concepts and findings in Great Britain. In: DIERKES, M.; HOFFMAN, U. (Eds.). New technology at the outset: social forces in the shaping of technological innovations. Frankfurt: Campus Verlag, 1992. p. 47-61.
YIN, R. K.

Case study research: design and methods. 2. ed. London: Sage Publications, 1994.

ZACCARELLI, S. B.

Estratégia moderna nas empresas. São Paulo: Zarco, 1996.

Estratégia e sucesso nas empresas. São Paulo: Saraiva, 2000.

ZUCKER, L. G.

Organizations as institutions. In: BACHARACH, S. B. (Ed.). Research in the sociology of organizations. Greenwich, Conn.: JAI Press, 1983. v. 2. p. 147.

Institutional theories of organization. Annual Review of Sociology, n. 13, 1987. 